\title{
Coach decision-making in Futsal: from preparation to competition
}

\author{
João Almeida, Hugo Sarmento, Seamus Kelly and Bruno Travassos
}

\section{QUERY SHEET}

This page lists questions we have about your paper. The numbers displayed at left are hyperlinked to the location of the query in your paper.

The title and author names are listed on this sheet as they will be published, both on your paper and on the Table of Contents. Please review and ensure the information is correct and advise us if any changes need to be made. In addition, please review your paper as a whole for typographical and essential corrections.

Your PDF proof has been enabled so that you can comment on the proof directly using Adobe Acrobat. For further information on marking corrections using Acrobat, please visit http://journalauthors.tandf.co.uk/production/acrobat.asp; https://authorservices.taylorandfrancis.com/how-to-correct-proofs-with-adobe/

The CrossRef database (www.crossref.org/) has been used to validate the references. Changes resulting from mismatches are tracked in red font.

\section{AUTHOR QUERIES}

Q1 Please provide missing department/city for this affiliation (a).

Q2 Please note that the ORCID for Hugo Sarmento has been created from information provided through CATS. Please correct if this is inaccurate.

Q3 Please note that the ORCID for Seamus Kelly has been created from information provided through Manuscript. Please correct if this is inaccurate.

Q4 Please note that the ORCID for Bruno Travassos has been created from information provided through Manuscript. Please correct if this is inaccurate.

Q5 Please provide missing department for this affiliation (b).

Q6 As per journal style abbreviations are allowed. Please check and provide if any.

Q7 The reference "Afonso (2012)" is cited in the text but is not listed in the references list. Please either delete in-text citation or provide full reference details following journal style [Standard APA]

Q8 The year for "Guzmán and Calpe-Gómez, 2012" has been changed to 2011 to match the entry in the references list. Please provide revisions if this is incorrect.

Q9 The CrossRef database (www.crossref.org/) has been used to validate the references. Mismatches between the original manuscript and CrossRef are tracked in red font. Please provide a revision if the change is incorrect. Do not comment on correct changes. 
Q10 The reference "de Moura et al., 2013" is listed in the references list but is not cited in the text. Please either cite the reference or remove it from the references list.

Q11 The reference "Dittrich et al., 2011" is listed in the references list but is not cited in the text. Please either cite the reference or remove it from the references list.

Q12 The reference "Hamid et al., 2014" is listed in the references list but is not cited in the text. Please either cite the reference or remove it from the references list.

Q13 The reference "Jovanovic et al., 2011" is listed in the references list but is not cited in the text. Please either cite the reference or remove it from the references list.

Q14 Please provide missing volume number for the "McCluney et al., 2018" references list entry. 


\title{
Coach decision-making in Futsal: from preparation to competition
}

\author{
João Almeidaa,b, Hugo Sarmento $\mathbb{D D}^{c}$, Seamus Kelly $\mathbb{D}^{\mathrm{d}}$ and Bruno Travassos $\mathbb{D}^{\mathrm{e}}$ \\ aLoughborough University Futsal and International Futsal Academy, Portugal; bUniversity of Beira Interior, \\ Covilhã, UK; 'Research Unit for Sport and Physical Activity (CIDAF), Faculty of Sport Sciences and Physical

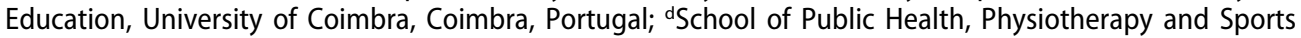 \\ Science, University College Dublin, Dublin, Ireland; 'Research Centre of Sport Sciences, Health Sciences and \\ Human Development (CIDESD), Department of Sport Sciences, University of Beira Interior, Covilha, \\ Portugal
}

\begin{abstract}
The purpose of this paper was to analyse the process of decisionmaking from preparation to competitive moments of expert futsal coaches. Ten expert and professional coaches' ( $M=46,9 \pm 7,93$ years old and $M=15,4 \pm 7,22$ years of coaching experience) from different countries were interviewed using a semi-structured interview (quantitative and qualitative) with two different goals: (1) evaluate the preparation for decision-making moment during the game; (2) classifying the importance of different game related points for decision-making during match moment. The data analysis was processed through combination of deductive and inductive methods through software QSR NVivo 11. The results revealed that coaches' share similar ideas to prepare their teams. That is, coaches focus first their attention on their own team identity and frame and second on opposition team behaviour and frame. It was also possible to identify clear coaching behavioural signs possible to be structured as cues and guiding lines for their decisionmaking process and actions before and during competitive moments. Such information can be important for the development of most appropriated coaching education curriculums according to game demands specificities.
\end{abstract}

\section{ARTICLE HISTORY}

Received 19 June 2019

Accepted 24 July 2019

\section{KEYWORDS}

Team sports; game plan; game management; coaching; scouting

\section{Introduction}

Futsal is 5 -a-side indoor football with unlimited number of players' substitutions in which game dynamics require that coaches constantly adjust behaviour of their own team according to the opposite team in a short time. It is an unpredictable and everchanging game in which every decision needs to be done at the right time under game pressure (McCluney, McCulick, \& Schempp, 2018). That is, for a good performance analysis that supports the coach intervention over the game, there is a need to define the most important information that coaches and also performance analysts need to attend to improve decision-making and action (Travassos, Davids, Araujo, \& Esteves, 2013).

CONTACT João Almeida jnalvesalmeida@gmail.com $\Theta$ Loughborough University Futsal and International Futsal Academy, Portugal

(c) 2019 Cardiff Metropolitan University 
However, more than to consider the predefined collective, strategical and tactical moves that should be considered, the coach should also must prepare himself with information from previous competition of the own or the opposite team, to deal with game dynamics and prospectively view possible game scenarios and strategies to manage competition, without additional information (Sarmento, Bradley, \& Travassos, 2015).

All the development of a performance analysis system $2_{2}$ as well as the coach intervention before and during competition, requires a good understanding of game dynamics according to the team game model definition. That is performance analysts and coaches should continuously pick up new information and adjust the game strategies that allow each player to improve his own performance in individual actions, but more importantly to improve the own performance according to the collective game model (Sarmento et al., 2015). The team game model can be defined as a guideline that supports the identification of common possibilities for action for each player and team in relation to opponents for each game moment (i.e. attack, defence, transitions, set pieces) (Silva, Garganta, Araújo, Davids, \& Aguiar, 2013). Such guidelines are based on spatial-temporal relations between players, teams and opponents at different relational levels, according to variations in game scenarios. To consistently develop the team game model and more than that support the implementation of the game model it is important that the coach is aware of primary related functions such as: Setting the vision and strategy, shaping the environment, building relationships, conducting practices, preparing for and managing competitions, reading and reacting to the field and learning and reflecting (Icce \& Lbu, 2013). That is, the coach should ensure a prior platform of communication or information exchange with the players to shared game affordances that sustain their individual and collective behaviour (Silva et al., 2013).

Based on that, to improve the analysis of performance of their team according to the teams' game model and situational game constraints (i.e. changes of players off the field, changes of the structure of play, suffering or scoring one goal, committing a higher number of fouls or faults), and potentiates the game management, coaches should constantly capture the best information that allow appropriate momentary decisions but also the identification of prospective game scenarios. During this process, coaches and also performance analysts should manage and produce information to act in short time and be effective (Afonso, Garganta, \& Mesquita, 2012). Really, this is one of the key issues that distinguish the expertise in the coaching process in team sports (Afonso et al., 2012).

Q7 Afonso (2012) research revealed that expert coaches, in comparison with novices, usually have the ability to choose and manage the most reliable information that needs, from previous or actual performance, to prepare a game plan or to make decisions in circumstances of great imponderability. Furthermore, expert coaches have the ability to capture the relational dynamics between players and teams from different views and considering the influence of some situational and contextual variables. For example, Gómez, Méndez, Indaburu, and Travassos (2018) showed that the analysis of the attacks in overload in elite futsal matches integrates contextual-related variables (i.e. quality of opposition, match period, attacking team's fouls, opponent's fouls, match status, attack duration and match type) determining their effectiveness on the match outcome. To do that, performance analysts and coaches should focus the attention on the most reliable information that uncovers the results of actions over the game. In particular, they need to attend to the most reliable information from the game to identify and anticipate the best opportunities for his own players and team (Araújo, Hritovski, Seifert, Carvalho, \& Davids, 2017). That is, 
coaches should develop the capacity to integrate different information from performance analysts and also from the game to understand how the different team components interact together to find the best strategical option to improve performance (Araújo, 2006).

Over the last years, some research have been developed in futsal focused mainly on match analysis (Agras, Ferragut, \& Abraldes, 2016; Sarmento et al., 2016) and on the game moments and the variables that should be considered to improve performance analysis during and after competition. However, few studies have focussed their analysis on the activities that coaches should develop to improve game understanding and the decision-making during the competition (Sarmento et al., 2015). Additionally, there are some studies (e.g. Baker, Côté, \& Abernethy, 2003; Kidman, 2010) that approach the athletes' decision-making processes with attempts to approximate or simulate real situations and to promote the understanding of this process to improve their performance over the competition. However, these types of studies in team sports were scarce with the process that coaches should develop to integrate the different information from game model, performance analysts and actual game competition. In line with previous assumptions, the purpose of this study was to analyse how coaches integrate information from previous performance and opponents to prepare the decision-making processes in competitive moments. Also, this study also intends to identify the critical information used by coaches during competition to improve the performance of the team.

\section{Methods}

\subsection{Participants}

Ten expert professional top futsal coaches (Ericsson, 2014) from different countries (i.e. Portugal, Spain, England, Croatia, Argentina and Brazil) participated on this study. Coaches aged 46,9 $\pm 7,93$ years old with a minimum age of 36 and a maximum of 60 years old. All the coaches held professional positions as a first team coach ranging from 7 to 28 years' experience $(15,4 \pm 7,22$ years). All coaches gave prior consent to participate in this study. Due to the in-depth nature of each interview, the interpretational nature of the analysis, the criteria for expert selection (i.e. international experience with notorious curriculum, experience in the most developed leagues in the world) allow us to consider the sample representative of expert coaches.

\subsection{Instruments}

To access the coach's perceptions, semi-structured interviews were used (Bardin, 2008; Flick, 2005). The interview guide was designed with two different purposes: (1) characterise the coaches' preparation decision-making and actions during performance, and; (2) identify the different game situations that might influence the game dynamics and teams' performance. The interview has been previously validated according to common qualitative methods (Creswell, 2007; Steinar, 2009). Final interviews were developed after exploring different opinions of previous drafts of the transcript using the following steps: (1) adaptation of first draft to the transcript based on the specific aims of the study; (2) evaluation of the interview transcripts by three senior researchers 
in sports pedagogy, who have substantial experience with qualitative methods and also by one Futsal coach with vast experience and high achievement; (3) opinions discussion and feedbacks presentation by each; (4) a pilot study conducted on a coach with similar criteria with the coaches included in the study; (5) minor fixes and adaptations resulting from the pilot study overview; (6) resubmission of the updated version of the interview guide to the experts, that resulted in the final version. It was composed by five general questions for open answers, and nine closed questions that require the coach to quantify in a scale (one not important to five really important) the importance of different game situations that might influence coach decision-making. The answers were used as a starting point for a more in-depth discussion on the information that coaches used to support performance analysis and decision-making before and over the competition.

\subsection{Data collection}

All the interviews were conducted by the first author between November 2017 and March 2018 via Skype using the software Eaver to record the video call conversation. The interview began with the presentation of general information and the purpose of the study, followed by two personal and informal questions related to their background, with the purpose to familiarise and promote coach relaxation. None of the coaches were rushed, and the opportunity was given for elaboration, restructure and even reformulation of answer. The interviews took between 35 and $20 \mathrm{~min}$ and were transcribed verbatim and this resulted in 74 pages, with font Calibri Body size 12 multiple line spacing. All the coaches were assigned a number to their transcription to ensure coach anonymity.

\subsection{Data analysis}

\subsubsection{Qualitative analysis}

The analysis of the coaches' preparation for game momentary actions was performed using content analysis (Bardin, 2008), and combining inductive and deductive approaches. The categories were established a priori (Team Identity, Opposition Team Weaknesses, Opposition Team Strengths, Team Composure for each Match Moment, Related to Own Team, Related to Opponent Team, Opponent Revision, Personal Focus, Prepare Final Instructions and Strategy, Develop and Learn with Mistake) (Afonso et al., 2012; Guia, 2009; Silva et al., 2013) and a posteriori during the qualitative analysis (Competitive Moment, Set Pieces, Quartets for Each Match Moment, External Factors, Refereeing Decisions, Prepare for Game External Factors, Assume if Needed, Keep Same Attitude). After the transcription process, the interviews were subject to a line-by-line analysis, which formed the basis of a thematic analysis to establish the emergent themes (Côté, Salmela, Baria, \& Russel, 1993; Creswell, 2007). Transcripts were read repeatedly for familiarisation of the underlying data (Creswell, 2007). The software QSR NVivo 11 was used in coding the transcripts of the interviews.

In order to establish trustworthiness, different techniques were used: (1) All researchers were trained in the methods of qualitative research, as outlined by several respected sources (Creswell, 2007; Smith \& Caddick, 2012); (2) Member checks (the 
most crucial technique for establishing credibility) occurred at the end of each interview during a debriefing session, and; (3) a peer review process that involved a neutral party was developed in order to ensure data credibility. An independent researcher examined the total of the meaning units and any disagreements were solved by consensus with the main researcher.

\subsubsection{Quantitative analysis}

The qualification of different game situations that might influence coach decision-making was based in data from the nine closed questions. To analyse the data, frequency analysis was performed with the software SPSS version 25 (IBM Corp., Armonk, NY), allowing to understand the relevance of each referred component in each question.

\section{Results}

The results were divided into two different parts according to the methodologies used and to highlight coaches' preparation for game momentary action and the game situations that might influence coach decision-making.

\subsection{Coaches' preparation for game momentary actions}

Results revealed five categories (i.e. identified problematic situation) and eighteen subcategories (i.e. solutions and strategies of intervention) that characterises coaches' preparation for game actions. The five categories that characterise coaches' preparation for game actions were: (1) personal preparation; (2) strategic preparation; (3) planned actions for the game; (4) game decisions, and; (5) management of wrong decisions (Figure 1).

In the category "priorities for a strategic game preparation", coaches highlighted: (i) the team identity; (ii) opponent team strengths; (iii) opponent team weakness, and; (iv) the competitive moment. From the analysis, it was possible to understand that working and developing their own team is a key issue over the micro-cycle of preparation for the game, giving attention to the game dynamics and to the structure that support the team identity. From this, the coach evaluates how to reply to the opponent strengths and how to attack the opponent weaknesses according to their own team identity. Connected to all of this, the competitive moment, the calendar, and the season goals should be considered in the preparation for a game.

The first one is how we play and how we develop in long term, our identity and how we want to play in the future, but to reach here we need to understand our position and also to develop one way to win, so, the first value is how we want to play, the second value is to make sure there is development, and the third one is to find a way to win without compromise the other two values. (Coach 5)

I think I should look for the individual intention and potential from each team and how this go in the team pattern, because this is the easiest thing to focus, these repetitive moments, because I can work this, more than game situation. (Coach 2)

In the category "planned actions for the game", coaches highlighted: (i) the team composure for each match moment with variations in team game strategies to the match according to the situation and also to the opponent set plays, (ii) set-pieces according to 


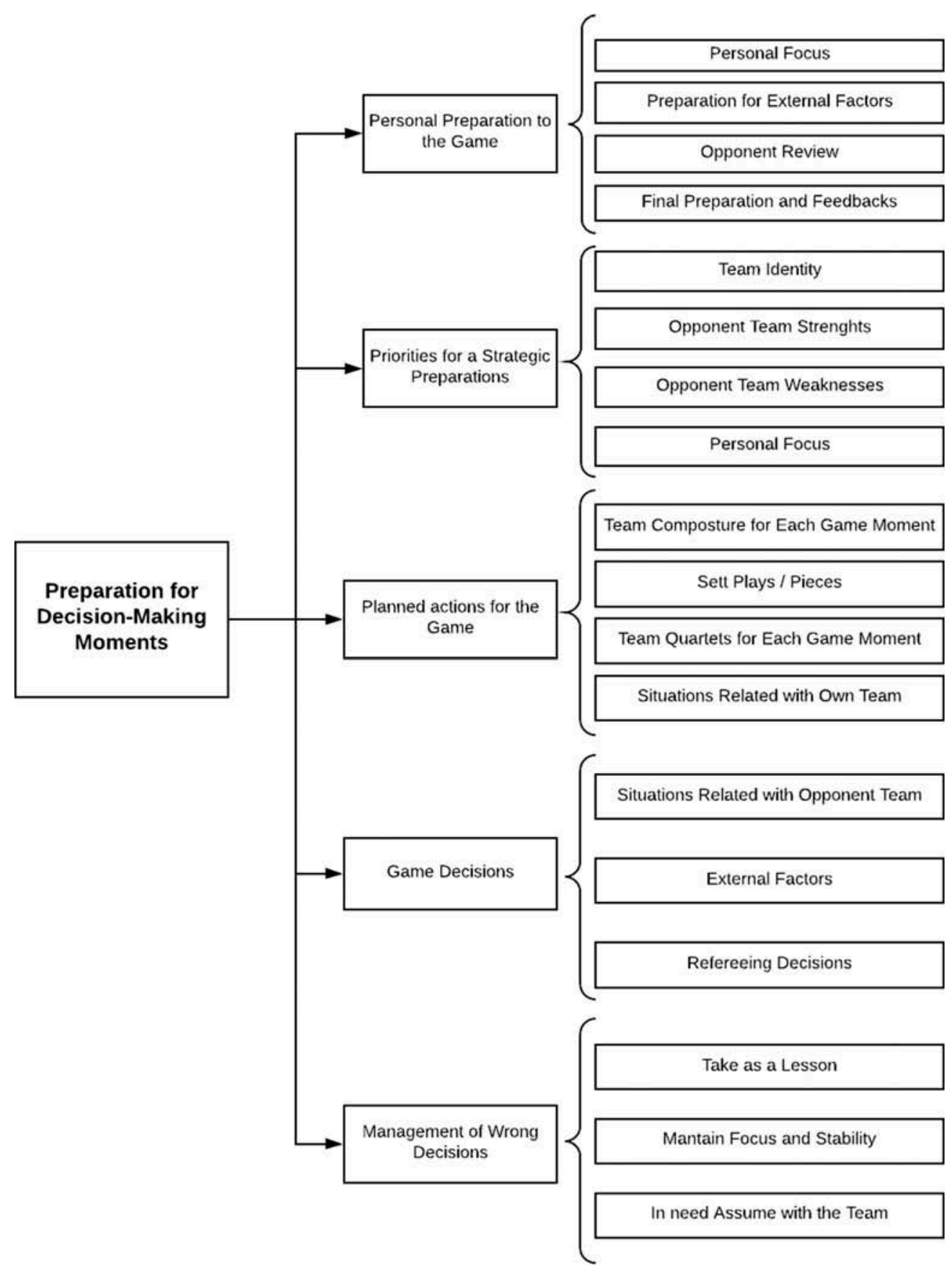

Figure 1. Categories that characterise coaches' preparation for game actions.

the opponent defensive system or to the offensive identified strategy, (iii) the preparation of team quartets for each match moment and according to the opponent approach that will suit better to different match moments according to the team characteristics, and (iv) own team strategy according to different match situations. With the definition of such strategical 
actions for the match, the team and the coach can act instantaneously when pre-identified match situations occur. It was possible to understand the concern of coaches to have a maximum of situations predicted with the definition of different game strategies to each one.

Usually we divide the match in game situations and we created what we call team modelling, with specificity in defensive moments, offensive moments and formations in four against four, so, we have three or four formations or schemes ready to play in different game situations. (Coach 4)

From before we already planned, we will take situation A or B instead of the $\mathrm{C}$, we also know $\mathrm{C}$, but the priorities are the others because we saw can give us more chances than the others. (Coach 7)

In the category, "game decisions", coaches highlighted the intervention on situations in which it is impossible to foresee and need momentary adaptations. In general, coaches referred to situations that related with their own team, such as: (i) abnormal performance from one player of his own team; (ii) situations related with opponent team, such as the use of different or new strategies in the match, and also, (iii) situations related with external factors, such as pitch conditions, and/or refereeing decisions. That is, these types of situations are not usually integrated in the match plan, but coaches should be aware of it.

You can study very well the opponent, you can prepare one incredible scouting and have one incredible week of trainings, and then in two minutes at the beginning of the match everything can go down just because, maybe in that day, the players aren't in a good mood, or maybe they have some personal problems affecting them. (Coach 3)

Any drastic change on the opponent team, for example they can change all their organization and system, in the defensive or offensive moments. (Coach 8)

In the category "personal preparation to the game", coaches highlighted the importance to work the personal focus, understanding the game dynamics and maintaining the maximum availability to make decisions and understand the competitive moment. Also, coaches mentioned the preparation of reactions and intervention on occurrence of external factors. The revision of the game plan, the opponent review and the final preparation to the match, including the main message and feedback for players are also fundamental moments that should be prepared before the game. For example, it is important for the coach to display positivity and confidence for the match and it is important that the coach control their own posture and behaviour before and during the match.

I think that the mentality must be worked, and I believe the psychological part of the team and Coach must be worked. If I am working all the week training at sixty per cent of my focus, I don't change that in the match, I am very intense and focused during all the week and in the match must be the same. (Coach 1)

When the match comes, I want to be ready to know everything and to know which players from the opponent is missing or not, how they play, if they have any problem, I try to collect as much information as I can, but for my coverage, I don't tell all this to the player. (Coach 6)

In the category "management of wrong decisions", coaches understand that mistakes and errors are part of the game. In line with that, it was referred that mistakes are 
lessons and there is a need to maintain focus and stability after mistakes. Analysing it and understanding the causes of the errors could avoid the repetition of that mistake, because the errors are already part of the past and the match keeps rolling.

I make a mistake and I see that was a wrong choice, we (coaches) take decisions in our job, with our knowledge and in some moments, for example, there is an important player to attack or to defend and I planned it wrong, sometimes the mistake happens, and we need to assume and learn with it. My work method always takes the mistakes as a reality and I just want to learn with them, mistakes always happens, from coach, from players, we have one second to take a decision, sometimes will help you other times will be against you. We need to work to don't repeat the same mistake and that's the most important after all. (Coach 9)

It's one immediate situation, you know you made a mistake, sometimes you take something and isn't working, but I know that's normal, everything is moving, it's hard in that moment to take a decision supported in things that you have prepared, sometimes the game come in the opposite way that you were expecting. I know, and I see my mistakes, but that don't take my feelings and my trust because I know all my moves and choices are to win the game, to improve the team and our winning possibilities. So, I am relaxed with that, I react with the biggest tranquillity that can exists and try to hide the mistake, not from the players, but the impact my mistake will give to the game must be hided. We need to react to hide it, because the player has to keep going confident. (Coach 4)

\subsection{Game situations that might influence coach decision-making}

The analysis of the questionnaire results highlighted the relevance of different game situations on coaches' decision-making (Figure 2).

Results revealed that the most important game situations on coaches' decisionmaking are: (1) collective behaviour; 2) individual behaviour and; 3) the last game. For the coach, it is important to prepare the overall team approach (collectively and

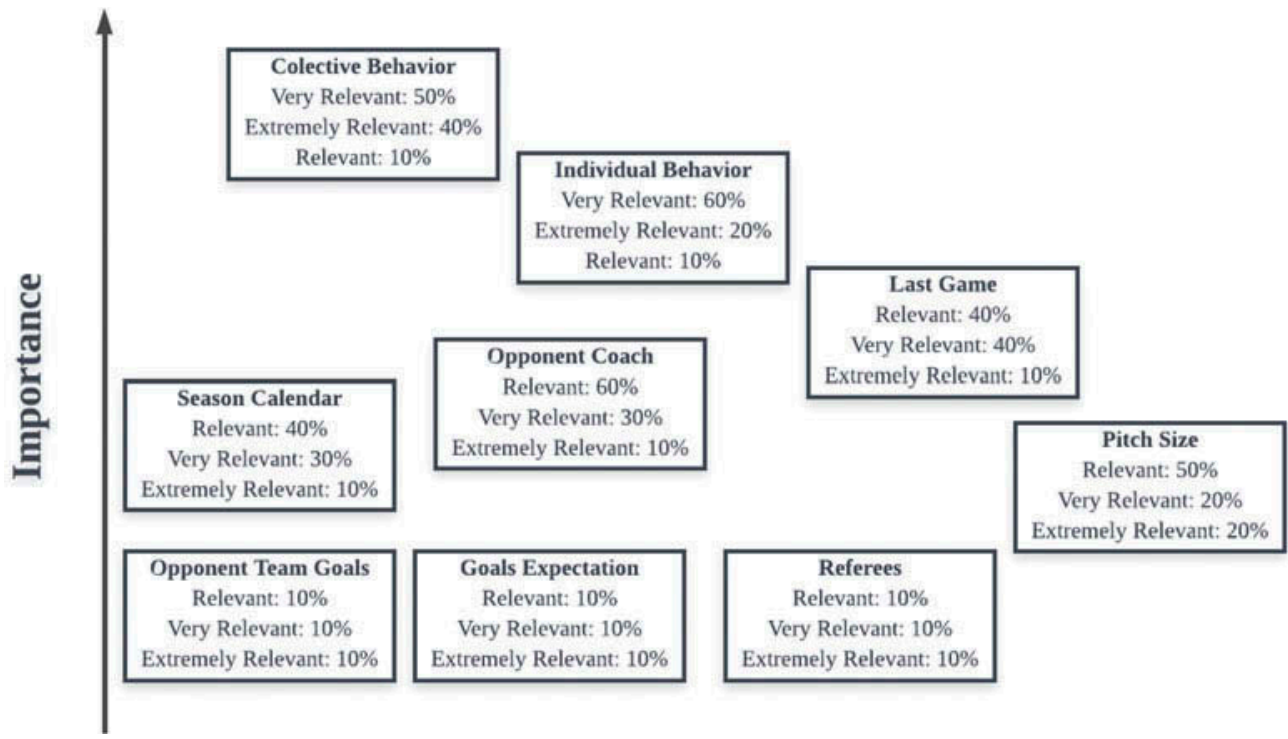

Figure 2. Game situations that influence coaches' decision-making. 
individually) over the week based on the information's given by the last match, in order to be increase the preparedness to the next competitive moment. After that, the knowledge regarding the opponent coach (i.e. playing style, game strategy, etc.) is also mentioned as an important factor that constrains coaches' decision-making.

Interestingly we can observe that "opponent team goals" and "referees", are variables that coaches cannot control, are game situations reported with few importance for decision-making of coaches. Also, "goals expectations" were reported as variables with limited importance concerning the decision-making process of coaches, maybe because of the focus on the process more than on the game result.

\section{Discussion}

The purpose of this study was to analyse the process of decision-making in competitive moments of expert futsal coaches. For that, a quantitative and a qualitative analysis of coaches' perspectives was collected and analysed in order to uncover the critical information used by coaches to prepare the decision-making before and over the match. According to the expectations, results highlighted that elite futsal coaches follow very similar ideas to manage their teams and to prepare the competitive moment. The preparation moment was centred on priorities, related to the own team identity and on the behaviour for the game. Such process has been referred as a breadth-first approach to problem-solving (Abraham \& Collins, 1998; Johnson, Johson, Murayama, Skon, \& Nelson, 1981; Zeitz \& Spoehr, 1989). There is weekly work to develop the knowledge of the opponent team and to develop the own team game performance and posture, generating perceptual information, which, in turn, constraints the emergence of further reactions (Araújo et al., 2017).

With the perception of most dangerous actions and limitations, and the identification of the most reliable information of the game coaches improve their capacity of anticipation (Williams \& Grant, 1999) to avoid the opposing team strengths and to take advantage of their weaknesses, whilst always staying faithful to their team's main identity, principles and posture.

As referred to by one of the interviewed coaches, the first priority is how your own team play and how to develop it in long term. The identity and the vision for the future should be the first value (i.e. the plan for the team, how to play). The second value is to make sure that the process of development if growing and the third value should be how to find a way to win without compromise the other two values.

External factors such as the pitch, referees, supporters or internal vision and project from the opponent team, are data that cannot be controlled by the technical team and own team, making them last of the concerns to the match preparation and those match characteristics come in the coach personal preparation to the match.

For coaches own preparation, first, there is focus on their own participation and the fact that they need to be aware of everything that is possible to share and how it may impact the team. Focus and posture should be prepared, as well the way to deal with frustration and match feedback, because any positive feedback can motivate but also can bring one less understanding of need to improve their actions, and negative feedback can fix problems but can also increase doubt and insecurity that generate

Q8 negatives actions (Guzmán \& Calpe-Gómez, 2011). Although the intrinsic feedback is vital when running a skill, the coach's responsibility is to provide the best possible 
external feedback that allows the athlete to accurately compare what he has done with what was intended to do. After there is the preparation for the external factors and one review from the opposition to adjust the own team for the game challenges with the final advice before the match. This final feedback is also prepared by coaches to increase players' awareness to the developed queues during the game preparation and to push the focus to the maximum level according to all the external factors, team goals and opposition. Attesting the importance that coaches' give to the pre-match speech preparation, the research of Vargas and Short (2011), indicates that the pre-match speech has the potential to be a highly influential coaching technique.

Regarding how to manage wrong decisions, coaches understand it is part of the game and is part of the general principle of lifelong learning process, based on experience and taking any mistake in deep analysis with the purpose to understand the reasons and to learn with it. In Pensgaard and Ursin (1998) research, some athletes mentioned that they have problems dealing with coaches' dissatisfaction and lack of control and emphasised that these problems were having a negative effect on their performances. According to that, coaches' show concern in the match preparation including the maintenance of stability with the goal to not affect the team and be aware that the team need the maximum focus from the coach. As mentioned by one of the interviewed coaches, the match is too fast and wasting time thinking about any possible mistake will increase the possibility to make more mistakes, so the focus must be high in subsequent moments.

The global idea is that the coach should be aware of what he can control, leaving what he can not control out of his focus and saving the time focussing and preparing for what it is controllable. Game components such as refereeing decisions, external factors and the reality of the opposition team is not something that should be in the coaching pre-match preparation due to be the impossibility of it being able to be controlled by the coach. Also, they should not spend focus and time with momentary decisions that can be planned; coaches' should instead focus their time with set pieces, team composure for different match moments and team quartets for different match approaches.

\subsection{Coach education implications}

The participants in this study can be viewed as expert coaches (Ericsson, 2014) based on their considerable professional coaching experience at the elite international level in futsal. Arguably these coaches are aware of the myriad of processes and factors underpinning decision-making, the mechanisms to develop decision-making skills (Araújo et al., 2017) and the impact of psychological factors on their players' decision-making process (Tenenbaum, Basevitch, Gershoren, \& Filho, 2013). However, we do not know if this expertise was gained from previous playing and/or coaching experience or from formal professional qualifications or informal sources (i.e. conferences, seminars, workshops, etc.). Nevertheless, we argue that coach education programmes should contain structures and processes for directly teaching or nurturing the development of decisionmaking skills with coaches, their athletes and consider how coaches are educated and trained to apply the decision-making skills at specific age-groups and levels. For example, modules focussing specifically on decision-making can be embedded within the curricula of formal coach education pathways provided by national sports federations. Decisionmaking focussed informal learning activities and coaching events (e.g. UEFA Futsal 
Coach Education Event) could also utilise academic and coach experts. Arguably, an understanding of the different theoretical perspectives (i.e. cognitive, social-cognition, economic, ecological dynamics) underpinning decision-making would assist coach educators in developing decision-making and how these factors impact coaches' decisionmaking processes. In 2012, UEFA expanded its futsal coach education activities when they introduced the UEFA Futsal Introduction, A, B \& C licences (UEFA, 2017) and also produced a futsal coaching manual designed to provide assistance for national football associations and coaches. While a number of studies have explored aspects of coaching and coach education in Portugal (Mesquita, Isidro, \& Rosado, 2010: Resende, Sequeira, \& Sarmento, 2016) and futsal (Serrano, Shahidian, Sampaio, \& Leite, 2013), further research are required to explore how the decision-making content that is integrated into these licences impacts coaches decision-making processes during the decision-making moment in a competitive context.

\subsection{Conclusion}

This article allows the identification of a regular perspective on the preparation of the competitive moments, promoting the development of futsal coaches in this area, with more practical and objective instruments available for futsal coaching education programs. According to the coaches' perspectives, it was possible to connect their ideas and find general instructions to understand and extract the prioritisation principles to find each solution.

In general, the most referred principles by the expert futsal coaches and that should always be in the coaches' mentality for the game preparation are: (1) own team identity; (2) have different solutions always prepared according to the team identity and to present in different moments or as an answer to different problems; (3) always know the players and understand the income and outcome of each one; (4) to complete analysis of the opponent team based on their weaknesses and strengths, and according to the own team identity construct the match strategy; (5) coaching is one position with continuous learning moments and all the mistakes should be part of that, analysed and fixed; (6) focus and stability never should be affected by any situation or match moment; (7) have an open relationship with the technical team, to receive the maximum income from it, but always develop the working process; (8) any change from the match plan can happen if the opponent team make a change that affects all their game identity; (9) all the plan should focus in what is possible to be controlled by coaches and own teams, not wasting time with game components impossible to manage.

\section{Disclosure statement}

No potential conflict of interest was reported by the author.

Hugo Sarmento (D) http://orcid.org/0000-0001-8681-0642

Seamus Kelly (D) http://orcid.org/0000-0002-2218-7940

Bruno Travassos (D) http://orcid.org/0000-0002-2165-2687 


\section{References}

Abraham, A., \& Collins, D. (1998). Examining and extending research in coach development. 410

Q9 Journal Quest, 50(1), 59-79.

Afonso, J., Garganta, J., \& Mesquita, I. (2012). Decision-making in sports: The role of attention, antecipation and memory. Brazilian Journal of Kinanthropometry and Human Performance, $14,592-601$.

Agras, H., Ferragut, C., \& Abraldes, J. A. (2016). Match analysis in futsal: A systematic review. International Journal of Performance Analysis in Sport, 16(2), 652-686.

Araújo, D. (2006). Tomada de Decisão no Desporto. Lisboa: FMH Edições.

Araújo, D., Hritovski, R., Seifert, R., Carvalho, J., \& Davids, K. (2017). Ecological cognition: Expert decision-making behaviour in sport. International Review of Sport and Exercise Psychology, (1-25).

Baker, J., Côté, J., \& Abernethy, A. B. (2003). From play to practice: A development framework for the acquisition of expertise in team sport. In J. Starkes \& K. A. Ericsson (Eds.), Expert performance in sports: Advances in research on sport expertise (pp. 89-113). Champaign, IL: Human Kinetics.

Bardin, L. (2008). Análise de Conteúdo. Lisboa: Edições 70.

Côté, J., Salmela, J., Baria, A., \& Russel, S. J. (1993). Organizing and Interpreting unstructured qualitative data. The Sport Psychologist, 2, 127-137.

Creswell, J. (2007). Qualitative inquiry \& research design, choosing among five approaches. Thousand Oaks: Sage Publications.

de Moura, N. R., Borges, L. S., Santos, V. C., Joel, G. B., Bortolon, J. R., Hirabara, S. M., \& Hatanaka, E. (2013). Muscle lesions and inflammations in futsal players according to their tactical positions. Journal of Strenght and Conditioning Research, 27(9), 2612-2618. doi:10.1519/JSC.0b013e31827fd835

Dittrich, N., Silva, J., Castagna, C., Lucas, R., \& Guglielmo, L. (2011). Validity of Carminatti's test to determine physiological indices of aerobic power and capacity in soccer and futsal players. Journal of Strength and Conditioning Research, 25, 3099-3106.

Ericsson, K. A. (2014). Why expert performance is special and cannot be extrapolated from studies of performance in the general population: A response to criticisms. Intelligence, 45, 81-103.

Flick, U. (2005). Métodos qualitativos na investigação científica. Lisboa: Monitor.

Gómez, M. A., Méndez, C., Indaburu, A., \& Travassos, B. (2018). Goal effectiveness after players' dismissals in professional futsal teams. Journal of Sports Sciences. doi:10.1080/ 02640414.2018 .1531498

Guia, N. (2009). Treino da Tomada de Decisão do Treinador: Análise da Influência dos Constragimentos Metadimensionais (Non Published Master Dissertation). Universidade Técnica de Lisboa - Faculdade de Motricidade Humana, Portugal.

Guzmán, J. F., \& Calpe-Gómez, V. (2011). Premilinary study of coach verbal behavior according to game actions. Journal of Human Sport \& Exercise, 7(2), 376-382. doi:10.4100/jhse.2012.72.04

Hamid, M. S. A., Jaafar, Z., \& Ali, A. S. M. (2014). Incidence and characteristics of Injuries during the 2010 FELDA/FAM National futsal league in Malaysia. Plos One, 9, 4. doi:10.1371/

Q12 journal.pone.0095158

Icce, A., \& Lbu. (2013). International sport coaching framework (version 1.2). Illionois: Human Kinetics.

Johnson, D. W., Johson, R. T., Murayama, G., Skon, L. C., \& Nelson, D. (1981). Effects of cooperative, competitive, and individualistic goal structures on achievement: A meta-analysis. Psychological Bulletin, 89(1), 47-62.

Jovanovic, M., Sporis, G., \& Milanovic, Z. (2011). Differences in situational and morphological parameters between male soccer and futsal - A comparative study. International Journal of

Q13 Performance Analysis in Sport, 11(2), 227-238.

Kidman, L. (2010). Athlete-centred coaching: Developing decision makers. UK: IPC Print 460 Resources. 
McCluney, E. N., McCulick, B. A., \& Schempp, P. G. (2018). Factors triggering pressure on Basketball Coaches' in-Game decision-Making. The Sport Journal, 20.

Mesquita, I., Isidro, S., \& Rosado, A. (2010). Portuguese coaches' perceptions of and preferences for knowledge sources related to their professional background. Journal of Sports Science \& Medicine, 9(3), 480.

Pensgaard, A. M., \& Ursin, H. (1998). Stress, control, and coping in Elite athletes. Scandinavian Journal of Medicine \& Science in Sports, 8(3), 183-189. doi:10.1111/j.1600-0838.1998.tb00190.x

Resende, R., Sequeira, P., \& Sarmento, H. (2016). Coaching and coach education in Portugal. International Sport Coaching Journal, 3(2), 178-183.

Sarmento, H., Bradley, P., Anguera, M. T., Polido, T., Resende, R., \& Campaniço, J. (2016). Quantifying the offensive sequences that result in goals in Elite futsal matches. Journal of Sports Sciences, 34(7), 621-629.

Sarmento, H., Bradley, P., \& Travassos, B. (2015). The transition from match analysis to intervention: Optimising the coaching process in Elite futsal. International Journal of Performance Analysis in Sport, 15(2), 471-488. doi:10.1080/24748668.2015.11868807

Serrano, J., Shahidian, S., Sampaio, J., \& Leite, N. (2013). The importance of sports performance factors and training contents from the perspective of futsal coaches. Journal of Human Kinetics, 38, 151-160.

Silva, P., Garganta, J., Araújo, D., Davids, K., \& Aguiar, P. (2013). Shared knowledge or shared affordances? Insights from an ecological dynamics approach to team coordination in sports. Sports Med, 43, 765-772. doi:10.1007/s40279-013-00870-9

Smith, B., \& Caddick, N. (2012). Qualitative methods in sport: A concise overview for guiding social scientific sport research. Asia Pacific Journal of Sport and Social Science, 1(1), 60-73.

Steinar, K. (2009). Interviews: Learning the craft qualitative research interviewing. USA: Sage.

Tenenbaum, G., Basevitch, I., Gershoren, K., \& Filho, E. (2013). Emotions-decision making in sport: Theoretical conceptualization and experimental evidence. International Journal of Sport and Exercise Psychology, 11(2), 151-168.

Travassos, B., Davids, K., Araujo, D., \& Esteves, P. (2013). Performance analysis in team sports: Advances from an ecological dynamics approach. International Journal of Performance Analysis in Sport, 13(1), 83-95.

UEFA. (2017). UEFA Futsal coaching manual. UEFA.com. Retrieved from https://www.uefa.com/ MultimediaFiles/Download/uefaorg/CoachingCoachedu/02/50/17/35/2501735_DOWNLOAD. pdf

Vargas, T., \& Short, S. (2011). Athletes' perceptions of the psychological, emotional and performance effects of coaches' Pre-game speeches. International Journal of Coaching Schience, 5(1), 27-43.

Williams, A. M., \& Grant, A. (1999). Training perceptual skill in sport. International Journal of Sport Psychology, 30, 194-200.

Zeitz, C. M., \& Spoehr, K. T. (1989). Knowledge organization and the acquisition of procedural 500 expertise. Applied Cognitive Psychology, 3(4), 313-336. 